\title{
A Case Study on Marketing Strategy of Xiaomi
}

\author{
Ashok Panigrahi \\ Associate Professor, NMIMS University, Shirpur, Maharashtra. \\ E-mail: panigrahi.ak@gmail.com
}

Area/Section: Management.

Type of the Paper: Research Case Study.

Type of Review: Peer Reviewed.

Indexed in: OpenAIRE.

DOI: http://doi.org/10.5281/zenodo.3466131.

Google Scholar Citation: IJMTS

\section{How to Cite this Paper:}

Panigrahi, Ashok. (2019). A Case Study on Marketing Strategy of Xiaomi. International Journal of Management, Technology, and Social Sciences (IJMTS), 4(2), 46-52.

DOI: http://doi.org/10.5281/zenodo.3466131.

International Journal of Management, Technology, and Social Sciences (IJMTS)

A Refereed International Journal of Srinivas University, India.

IFSIJ Journal Impact Factor for $2018=4.764$

(C) With Authors.

This work is licensed under a Creative Commons Attribution-Non Commercial 4.0 International License subject to proper citation to the publication source of the work.

Disclaimer: The scholarly papers as reviewed and published by the Srinivas Publications (S.P.), India are the views and opinions of their respective authors and are not the views or opinions of the SP. The SP disclaims of any harm or loss caused due to the published content to any party. 


\title{
A Case Study on Marketing Strategy of Xiaomi
}

\author{
Ashok Panigrahi \\ Associate Professor, NMIMS University, Shirpur, Maharashtra. \\ E-mail: panigrahi.ak@gmail.com
}

\begin{abstract}
With the intense development and growth of China's mobile communication and technology industry, many manufacturers have come up to take the advantage of growing market of mobile phone users. Approximately 1 billion people own a smartphone. This has led to birth of many of the world's famous mobile phone brands. One of the major brand, emerged in 2010 was Xiaomi. In this paper, background of Xiaomi's, its marketing strategies, business models have been presented. Also, comparative analysis of marketing strategy of Xiaomi and other manufacturers has been done to understand the reasons for the market success and the exponential growth exhibited by the company. The current state of information available through various platforms has been used to perform the study. It has been inferred that, the primary reason for this exceptional growth has been the product quality at cheaper rate with a focus on customer feedback and requirements. The testimony to this fact is its ever expanding portfolio into various domains such as smart TVs, Speakers, home appliances, personal computers to name a few.
\end{abstract}

Keywords: Marketing Strategy, Xiaomi, Pricing, Branding, India.

\section{INTRODUCTION :}

In the last 5 years it has been observed that the smartphone industry has grown exponentially. Long gone is the time when the consumers needed to carry 2-3 kg laptops for their daily requirements. Nowadays big brands like Xiaomi have been adopting the strategies of hunger marketing where the availability of the product is intentionally restricted by the manufacturer to create surplus demand in the market. A major change has been identified in the usage pattern of consumers which has been strategically tapped by companies [2].

Xiaomi's first android based firmware MiUi was launched on $16^{\text {th }}$ August 2010 and a year later it launched is first smartphone Mi1 in China [5]. The product became successful and further new models were launched namely M2, M3 and Redmi phones on the domestic front. Xiaomi hired Hugo Barra (ex. Google Android Executive) who paved the way for its expansion in the offshore markets.

After successfully capturing significant market shares in the rest of Asia, Xiaomi entered Indian markets in July 2014. Initially Xiaomi made an exclusive partnership with ecommerce giant Flipkart to sell its smartphones but later on $7^{\text {th }}$ April 2015 they changed their distribution strategy and announced partnership with Amazon and Snapdeal.

They first started productions in Sricity (A.P.) at that time 200 million people owned a smartphone out of 1.2 billion people. By the end same year, they captured $1.5 \%$ of Indian market share which doubled in 2015 competing along with homegrown brands like Micromax, Lava and other international brands like Samsung.77\% of the smartphones were locally made that benefited them in reducing the operational costs. By the same time Xiaomi had overtook Samsung and Apple by the end of 2015 in China [2].

Xiaomi.inc which was ranked $2^{\text {nd }}$ amongst 50 other reviewed reputed companies (viz. Apple, Google, Microsoft etc.) by MIT technology review (2015). This happened just within a year Xiaomi stepped in the Indian markets.

\section{RESEARCH OBJECTIVES :}

The objective of this paper is to analyze the marketing strategies of Xiaomi and to find out its 
secret of success of in India

\section{MARKETING STRATEGIES :}

\subsection{Introduction to marketing strategy}

Penetration into any foreign markets requires various mix of marketing strategies which will impact success of any firm. It can be achieved in 2 ways. They can either use traditional marketing mix or can customize their existing mix according to the requirement of the country. If same marketing mix is used in the export country to attract customers, standardization strategy is normally used by the firm as it requires less investment as compared to adaptation strategy but the trends observed in the present scenario reveals that companies are customizing products according to consumer needs rather than providing a single product throughout its worldwide market [9]. Creating brand loyal customers is an important step to ensure future expansion and it can be done by exceeding their expectations [4].

Companies need to face competition in order to survive in the market. As smartphone manufacturing has gained momentum the primary way of having a competitive advantage and ensure survival it is important that firms maintain their profit margins while simultaneously expanding the customer base [11].

\subsection{Marketing Strategies adopted by Xiaomi}

Xiaomi has expanded and established itself as a valued startup and it has a chance of becoming the world's top most smartphone company. There are two basic competitive strategies followed by Xiaomi that are manufacturing products with superior qualities and features and produced at a lesser cost. In addition, there are certain extra features that are present in Xiaomi phones that drive the attention of the customers towards it. Before launching its phone, the company had surveyed the market aggressively and analyzed the competitive strategies of smartphone giants like Apple and Samsung. Those were having strong customer loyalty having a robust operating system that is Android. Android was chosen as the operating system and Xiaomi designed MI UI its own customized operating system based on Android with added cloud services, security, apps, music, video player, browser and many more common items [3]. The core competitive strategies adopted by Xiaomi competitive cost, quick expansion in the offshore markets, less margins and selling products online exclusively. Indian market is very diverse and large and it is difficult to penetrate it in one go hence Xiaomi chose a narrow segment to cater initially which aspired to produce a great product but at the same time at lower costs for the cost conscious customers. These are the following market strategies adopted by Xiaomi [6].

\subsection{Innovating the products}

Xiaomi always believed in a system in which there is continuous innovation not only for their operating system but also for their marketing strategies and programs. The products mainly smartphones manufactured by the company are of superior quality and their aimed to provide value for money proposition to their customers its sub brands known as MI and Redmi have been delivering great value for money smartphone models. Some of its famous mobile phones were 4S, MI 4 and Redmi Note 3. These mobile phones had rocked the market with huge sales and continue to do so with their latest upgraded models being released regularly by the company. Redmi Note 3 as per IDC was the highest shipped device in the history of online smartphone industry with more than 2.4 million within 6 months.

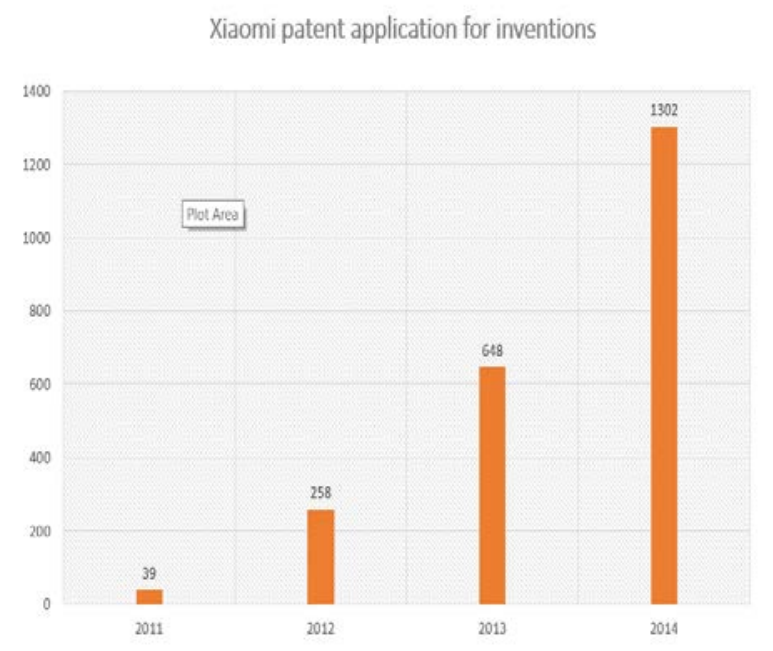

Fig.1: Number of Patent Applications

3.4 Focusing on aggressive pricing and maintaining high quality standards 
Initially, the markets were dominated by the smartphone giants like Samsung and Apple, and local players of the specific market and Xiaomi had realized that it is very difficult to compete with them and hence had to focus on expanding its customer base by providing high quality products and charging low premium for them. Xiaomi did this by offering limited number of products toward targeted customer base of range $10000-15000$ rupees in Indian market by reducing its advertisement cost by adopting the online advertisement strategies. Another way of reducing the price was exclusive partnership with online retailers like Flipkart and Amazon that reduced the logistic costs. These online retailers also had history of consumer satisfaction and trust which was also utilized buy Xiaomi.

\subsection{Minimum investment on conventional} advertising

Xiaomi was one of the few brands which promoted a unique marketing approach to appeal the market it was the brainchild of CEO of the company Lei Gen. Word of mouth publicity was used as it was believed by the company that satisfied customers create positive vibes in the market and it is also a cost effective way to penetrate into the other international markets. Minimum expenditure was made on traditional advertising and instead social media; online forums were used to connect with the target audience. The engineers of Xiaomi had direct contact with the consumers and hence helped them to gather useful information to overcome the difficulties and modify the software according to the consumer needs. Another plus point with Xiaomi was that it advertised itself as a consumer friendly brand with establishment of customer care centers which catered the problems and continuously improve upon them.

\subsection{Loyal fan base}

Xiaomi had created a huge fan following who were the early adopters and the first ones to buy MI UI smartphones they were known as MI- fans these were the people mainly consisting of bloggers, patrons who constantly created buzz on the internet about the company, its products and services it provided. China had a micro blogging platform with more than 400 million subscribers known as Sina Weibo and it was used as a medium for promotion. The company saw the potential of the app and decided to sell phones directly from it.

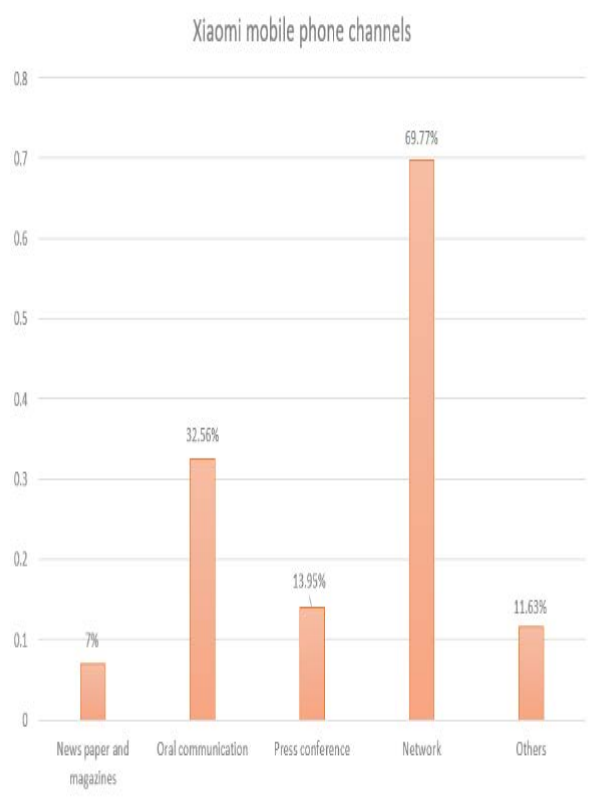

Fig.2: Number of Mobile Phone Channels

Now a days Xiaomi uses online channels like Flipkart, Snapdeal and Amazon for advertisement and selling of products to its target customers. Customers being the most important aspect also involve themselves completely in designing and development process where their inputs are taken through the online mediums such as social media sites, micro blogging platforms and are incorporated suggesting changes in the new products [1].

\subsection{Earning revenue from the software}

This strategy used by Xiaomi was one of its most effective strategies executed. Xiaomi, having excellent software based on Android having a customer base of more than 50 million users, Xiaomi developed its own themes, games and apps which work pre-installed on MI UI and helped contribute more than 6 million sales revenue on a monthly basis. Just like Amazon and other e-commerce Xiaomi worked and aspired to earn profits via its ecosystems and marketing various goodies. In recent times Xiaomi has allowed advertisement into sum of its apps installed on MI UI that further help generate 
revenue and has received mixed response from the consumers as well as critics.

\subsection{The method of flash sales}
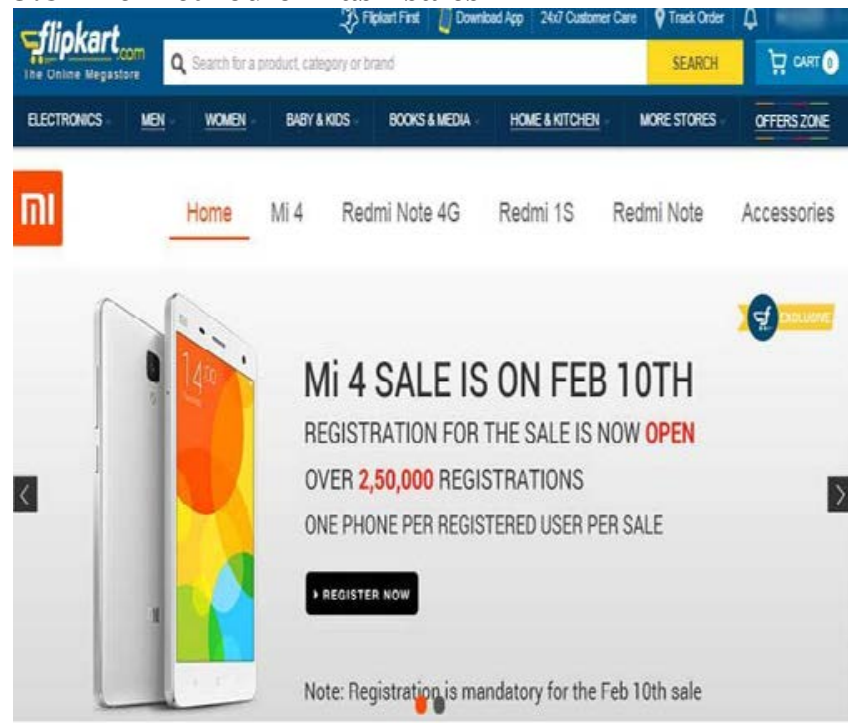

Fig. 3: Screenshot of Flash Sale (Source: http://st1.bgr.in/wp-content/ uploads/ 2015/ 02/

Xiaomi-mi-4-sale-numbers.jpg)

Older and more established brands like HTC, Samsung, Apple and many more local players make their products available in the market through third party retailers and stores but on the other hand Xiaomi does not follow this method and sells its products via online flash sales. In these flash sales a limited quantity of product is available for sale at a particular time, and the sale continues till the stock lasts with an intention to encourage customers to go for impulse buying. The limited quantity also motivates the customers to buy the product on spot this method increases the profits of the company, prevent the hoarding of stock and over production. The main advantage of flash sales is that it aids in inventory management avoid the over production and create scarcity. For example, a flash sale of company in which Xiaomi launched MI 4. It went on sale via Flipkart in 2015 and in the first flash sale the demand of the mobile exceeded it supply by at least 10 times.

\section{ENTRY INTO THE INDIAN MARKET :}

After its successful market domination in China Xiaomi's major move was to establish itself in India the company had to go neck to neck with domestic as well as international players already existing in the Indian smartphone markets. The new Indian customers were also apprehensive that their data would be directly accessed by the Chinese government India has a very diverse and competitive smartphone market and to be successful and survive and constantly evolve. Xiaomi had to focus on different strategies and product mixes to effectively target different segments. The segmentation was done mainly on the basis of four factors that were the Purchase power, the required functionality, the technology technological familiarity, and the intended use.

Hence three broad customer segments for defined-

(1) Entry level:

This consumer base of Xiaomi consists of people who belong to low socioeconomic classes and these people usually spend a very minor portion of their income on technology based products but they have a high level of curiosity in owning them. Pricing is always an important factor for this people and they always look out for cheaper substitute, they respond highly to advertising and the better the advertising the better is the chance of making them by the intended smartphone product.

(2) The mid-range consumers:

This group mainly comprises of the middle class people who are moving from the lower sections of the society towards the higher sections. They look for a reasonably priced product which has lot of value added features these people are ready to spend their earnings into new technological products provided they get the features they expect.

(3) High end consumers:

These consumers mainly comprise of the people coming from business backgrounds with high source of income and they mostly willingly invest in new and upcoming technologies dominated by big brands like Apple, Samsung etc. Xiaomi knew that these customers are not a big fish for them so it did not focus these customers initially but now after establishing itself in the lower and the middle segments it has started focusing this segment. 


\section{Consumers for house of Xiaomi views and attitudes}

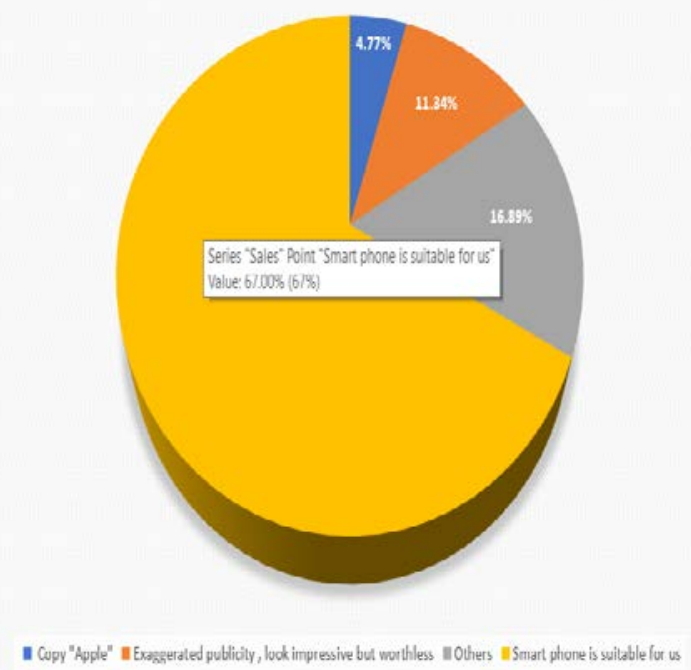

Fig. 4: Customer feedback

(4) Current scenario of Xiaomi in India:

People in India are very particular about some things when they purchase any product and quality is one of the major factors while choosing between different products. When we look into smartphones the main factor that decides the quality of a smartphone is its build quality. The build quality is all about the durability of the phone. The smartphone market is divided in to two categories in terms of build quality- metal and plastic. There is a mental block that keeps running in the minds of people which is, if a phone is priced low then the parts used in its manufacturing were not of the prime quality. This is not the case with Xiaomi's products.Xiaomi is among the brands which will give you a quality product at a very low rate and this is exactly how it captures most of its market. Now the question arises how it does that? There are many aspects which come into play when it comes to increasing the sales and this can be done with the help of marketing. Usually company spends a lot when it comes to marketing and the most they spend on is advertisements. This is exactly where Xiaomi takes the lead, it does not spend a lot on advertisements instead it directs most of its money flow into the R\&D and the manufacturing sectors and this is how it manages to keep a remarkable quality with such a price.

There has been little or no signs of slowing down of Xiaomi in India. This Chinese brand has registered and impressive 155\% annual shipment growth. Xiaomi has shipped around 9 million and has grabbed the market share of above $31 \%$ and this is the highest ever for a vendor since the quarter 1 of 2014 when Samsung had a share of $33 \%$. It has also been observed that the gap between Xiaomi and Samsung has increased. Samsung shipped 7.5 million smartphones, whereas Oppo took the third place with 2.8 million and Vivo the fourth place with 2.1 million units. In total, the smartphone market in India grew at $8 \%$ to 29.5 Million units for the first quarter of 2018.

Table 1: Market Sales in various countries

\begin{tabular}{|c|c|c|c|c|}
\hline $\begin{array}{l}\text { Global smartphone } \\
\text { sales (million in } \\
\text { units) }\end{array}$ & 2014 & 2015 & 2016 & 2017 \\
\hline United states & 405 & 458 & 491 & 505 \\
\hline India & 82 & 118 & 149 & 174 \\
\hline China & 148 & 164 & 167 & 169 \\
\hline others & 629 & 732 & 778 & 819 \\
\hline Total & 1265 & 1471 & 1585 & 1667 \\
\hline $\begin{array}{c}\text { Global smartphone } \\
\text { sales growth(year- } \\
\text { over-year) }\end{array}$ & 2014 & 2015 & 2016 & 2017 \\
\hline United states & - & $13 \%$ & $7 \%$ & $3 \%$ \\
\hline India & - & $43 \%$ & $26 \%$ & $17 \%$ \\
\hline China & - & $11 \%$ & $2 \%$ & $1 \%$ \\
\hline Others & - & $16 \%$ & $6 \%$ & $5 \%$ \\
\hline Total & - & $16 \%$ & $8 \%$ & $5 \%$ \\
\hline
\end{tabular}

Source: Strategy Analytics

\section{CONCLUSIONS AND FINDINGS :}

- Xiaomi has become one of the most valuable startup from valued currently at US 50 Billion Dollars. It made huge success in the smartphone selling business by implementing mix market strategies which have proven highly successful in the global as well as domestic markets.

- Xiaomi has marketed itself in the lower and mid-tier of the market and has not established or tried to establish itself only a premium product manufacturer which has become one of its biggest strength.

- The strategy of creating the buzz of a company which has also been adopted by top tier brands like Apple and Samsung has been successfully created by Xiaomi and has 
beaten Apple and Samsung on the price fronts.

- Adopting guerilla marketing as a way of reducing costs along with use of word of mouth publicity and building strong consumer bond has helped Xiaomi to come this far [8].

The study has helped to understand how well planned and perfectly executing marketing strategy of Xiaomi has helped it come this far and helped it over take international and critically acclaimed brands. There is a huge opportunity for Xiaomi that lies ahead.

\section{REFERENCES :}

[1] Ajax Persaud, I. A. (2012). Innovative mobile marketing via smart phones: Are consumers ready? Marketing Intelligence \& Planning, 30(4), 418-443. DOI: http:doi.org/ 10.1108/02 634501211231883.

[2] Rawal, P., Awasthi, A. \& Upadhaya, S. (2017). Creating a Hunger Driven Smartphone Market by Xiaomi. International Journal of Engineering Science and Computing, 7(5), 11250-11255.

[3] Haluk Koksal, M. and Ozgul, E. (2010). The export competitive advantages of Turkish manufacturing companies. Marketing Intelligence \& Planning, 28(2), 206-222.

[4] Jain, S. C. (1989). Standardization of international marketing strategy: some research hypotheses. The Journal of Marketing, 70-79.

[5] Kharpal, A. (2014). What's behind rapid rise of 'Chinas Apple' Xiaomi? [online] CNBC. Available at: http: //www. cnbc. com/2014/12/22/whats-behind-rapid-rise-ofchinas-apple-Xiaomi.html

[6] Kristianto, Y., Helo, P. and Takala, J. (2011). Manufacturing capabilities reconfiguration in manufacturing strategy for sustainable competitive advantage. International Journal of Operational Research, 10(1), p.82.

[7] Levitt, T. (1983). The Globalization of Markets. Harward Business Review, pp. 92102.
[8] Levinson, J.C. (1994). The Guerrilla Marketing Handbook, Houghton Mifflin, Boston, MA.

[9] Manker, A. (2014). What Is Guerrilla Marketing? -Definition, Strategies \& Examples Education.

[10] Portal. Education Portal. Retrieved 12 October 2014, from http://education portal.com/academy/lesson/

[11] Slater, Stanley, \& Narver, John (1994). Does competitive environment moderate market orientation performance relationship? Journal of Marketing, 58(1), 46-55.

[12] https://www.quora.com/What-is-themarketing-strategy-behind-Xiaomi-mobiles

[13] http://www.business-standard. Com/article/ technology /flash-sales-pricing-superiorproducts-how-Xiaomi-captured-india17010500365_1.html

[14] https://www.techinasia.com/10-strategiesXiaomi-secret-sauce

[15] https://www.mobilescout.com/android/news/ n91369/ Indian-smartphone-market-grew-522016-IDC.html

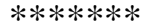

